\title{
Repeatability of Tensile Properties in High Pressure Die-Castings of an Al-Mg-Si-Mn Alloy
}

\author{
Hailin Yang ${ }^{1,2}$, Shouxun $\mathrm{Ji}^{1, *}$, Douglas Watson ${ }^{1,3}$, and Zhongyun Fan ${ }^{1}$ \\ ${ }^{1}$ Brunel Centre for Advanced Solidification Technology (BCAST), Brunel University London, Uxbridge, \\ Middlesex UB8 3PH, United Kingdom \\ ${ }^{2}$ State Key Laboratory of Powder Metallurgy, Central South University, Changsha 410083, China \\ ${ }^{3}$ Engineering Centre, Jaguar Cars Ltd, Abbey Road, Coventry, CV34 4LF, United Kingdom
}

(received date: 1 March 2015 / accepted date: 5 June 2015)

\begin{abstract}
High pressure die-castings of an Al-Mg-Si-Mn alloy have been assessed in terms of the repeatability of the mechanical properties including yield strength, ultimate tensile strength and elongation by the normal standard deviations method and by the Weibull statistical model with three parameters. It was found that the round samples had the maximum Weibull modulus, indicating the best repeatability. The machined samples exhibited the second best of Weibull modulus. Among the square samples, the $2 \mathrm{~mm}$ and $5 \mathrm{~mm}$ thick samples had the lowest and the highest Weibull modulus respectively, indicating that the repeatability for the castings was influenced by the wall thickness. The microstructural uniformity and porosity levels are critical factors in determining the repeatability of the high pressure die-castings. A less segregation in the microstructure could uniform the stress distribution in the die-castings and a less porosity in the casting could reduce the sources for brittle fracture. These improved the repeatability in casting production.
\end{abstract}

Keywords: alloys, casting, mechanical properties, microstructure, tensile test

\section{INTRODUCTION}

In vehicle manufacturing the development of thin-wall castings for use in automotive body structures is a key enabler for replacing steel with lightweight materials. This lightweighting is driven by the need to reduce $\mathrm{CO}_{2}$ emissions in the use stage of vehicles [1,2], reducing tailpipe emissions by increasing fuel efficiency through effective weight reduction of the vehicle [3,4]. The application of Al-Mg-Si-Mn alloys $[5,6]$ is one of the most recent developments for body structural castings.

In the manufacturing of thin-wall components by high pressure die-casting (HPDC) process, one of the most important characteristics is that the melt is filled into the die cavity with turbulent flow during casting [7]. This results in a high probability of forming defects, in particular porosities in individual die-casting. More importantly, the defect distribution in the die-castings is random and irregular, resulting in a large uncertainty in the mechanical properties and a poor repeatability between different types of die-castings and even in the same location of a casting made in different manufacturing cycles $[8,9]$. In reality, a relatively large design margin

*Corresponding author: shouxun.ji@brunel.ac.uk is usually given in order to compensate for the detrimental effect caused by the internal defects in die-castings. However, this significantly increases the casting weight, which is one of the major concerns in the specific structural applications for the automotive and aerospace industry. Therefore, the repeatability of castings becomes greatly important in the manufacturing of thin-wall castings.

The reliability and repeatability of castings can be effectively assessed by statistical distribution models, in which Weibull statistical analysis is one of the reliable methods to evaluate the variables in life and strength parameters on the basis of the weakest-link concept $[10,11]$. Weibull analysis is thus becoming more common in relation to examining the defects for strengths of brittle materials, especially for castings $[12,13]$. In the application of HPDC components, their tensile properties are usually assessed using samples either specially made during casting manufacturing or machined from existing castings. It is necessary to analyse the defects and microstructure with the resultant tensile properties and Weibull statistical parameters as a good guidance for engineering design and component manufacturing.

In the present study, the tensile properties were measured for a set of standard samples that were directly made by HPDC process and a set of samples that were obtained from machining samples from various locations of a larger automotive 
die-casting. These were used to assess the repeatability of cast components made from the Al-Mg-Si-Mn alloy. The distributions of the yield strength, ultimate tensile strength (UTS) and elongation of the samples were analysed by the average value with standard deviations and by the Weibull statistical model with three parameters. The correlations between the tensile properties and the microstructural features, porosity levels and fracture morphology were investigated for the different types of samples. The microstructure, defect levels and fractural graphical characteristics were examined in relation to the tensile properties of the alloy.

\section{EXPERIMENTAL PROCEDURES}

\subsection{Casting}

The Al-Mg-Si-Mn alloy was supplied by an industrial supplier with the measured composition of 4.90-5.11 wt $\% \mathrm{Mg}, 1.89$ $2.05 \mathrm{wt} \% \mathrm{Si}, 0.56-0.61 \mathrm{wt} \% \mathrm{Mn}, 0.16-0.18 \mathrm{Ti}, 0.08-0.1 \mathrm{wt} \% \mathrm{Fe}$, $10-12 \mathrm{ppm} \mathrm{Be}$ and $\mathrm{Al}$ as balance. During experiments, a top loaded electrical resistant furnace was used to melt the Al-Mg-Si-Mn alloy in a graphite crucible. A batch of $40 \mathrm{~kg}$ alloy was melted at a temperature of $710^{\circ} \mathrm{C}$ each time. The castings were made by a $4500 \mathrm{kN}$ cold chamber HPDC machine, in which all casting parameters were fully monitored and recorded. The pouring temperature was controlled at $700^{\circ} \mathrm{C}$, which was measured by a K-type thermocouple.

Two sets of die were used for the present study. One was employed to cast six ASTM standard samples with three $\phi 6.35 \mathrm{~mm}$ round samples and three square samples with cross sections of $6.35 \times 2 \mathrm{~mm}, 6.35 \times 3 \mathrm{~mm}$ and $6.35 \times 5 \mathrm{~mm}$, respectively [14]. The other die casting was an automotive component, and the casting structure with overflow and gating system is shown in Fig. 1. The typical wall thickness is $2.8 \mathrm{~mm}$ for the trial die-casting. The injection parameters were optimised for each type of casting and the castings were made under the corresponding optimised condition. The dies were heated by the circulation of mineral oil at $250^{\circ} \mathrm{C}$. All casting samples were kept in ambient condition for at least $24 \mathrm{~h}$ before the mechanical properties being tested. 20 pieces of such trial castings were selected for making tensile samples. 5 standard square samples with a cross section of $6.35 \times 2.8 \mathrm{~mm}$ were machined from each trial casting and the locations are marked in Fig. 1.

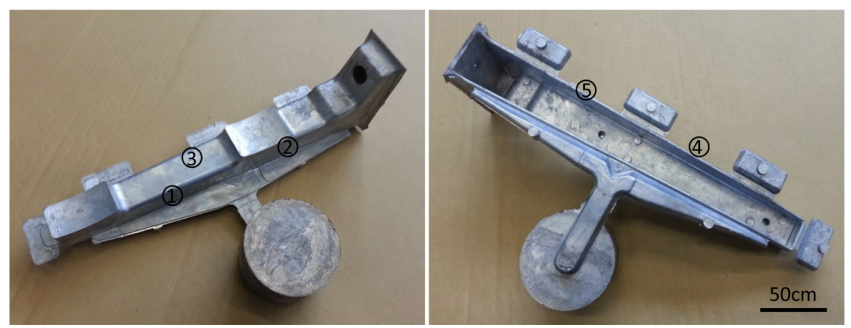

Fig. 1. The photos showing the casting structure with runner, over flow and biscuit for the evaluation of reproducibility.

\subsection{Microstructure and tensile property}

The tensile tests were conducted following ASTM standard B557, using an Instron 5500 Universal Electromechanical Testing System equipped with Bluehill control software and a $\pm 50 \mathrm{kN}$ load cell. All tensile tests were performed at an ambient temperature $\left(\sim 20^{\circ} \mathrm{C}\right)$. The gauge length of the extensometer was $25 \mathrm{~mm}$ and the ramp rate for extension was $2 \mathrm{~mm} / \mathrm{min}$. The microstructure was examined using a Zeiss optical microscope equipped with an AxioVision 4.3 Quantimet digital image analysis system for quantitative metallography and a Zeiss SUPRA 35VP scanning electron microscope (SEM) equipped with energy dispersive spectroscopy (EDS). The metallographic samples were prepared by a standard technique. The porosities were measured on a cross section of the polished sample without etching. Five different fields of view were analysed from each specimen and the average was taken as the actual measurement value.

\subsection{Repeatability and Weibull statistic analysis}

The Weibull distribution expresses the cumulative probability of failure as a function of maximum applied tensile stress acting in an effective volume of sample. The mathematic function is expressed as [18]

$$
\begin{aligned}
& P_{f}=1-\exp \left[-\left(\frac{\sigma-\sigma_{u}}{\sigma_{0}}\right)\right]^{m} \\
& \ln \left[\ln \left(\frac{1}{1-P_{f}}\right)\right]=m\left[\ln \left(\sigma-\sigma_{u}\right)-\ln \sigma_{0}\right]
\end{aligned}
$$

where $P_{f}$ is the cumulative fraction of specimen failures in the tensile test; $\sigma$ is the variable being measured (yield strength, UTS or elongation to fracture); $\sigma_{u}$ is the threshold parameter, i.e. the characteristic stress (or strain) below which no specimen is expected to fail; $\sigma_{0}$ is the scaling parameter, also called the characteristic stress (or strain) at which the probability of failure is $63.2 \%$; $\mathrm{m}$ is the shape parameter, also referred to as the Weibull modulus [15].

Equation (2) configures the three-parameter Weibull distribution. The double logarithm of the reciprocal $\left(1-P_{f}\right)$ can be easily plotted with $\ln (\sigma)$ because the $\ln \left[\ln \left(1 /\left(1-P_{f}\right)\right)\right] v s$. $\ln (\sigma)$ shows a straight linear relation with slope $m$ and intercept $-m \cdot \ln \left(\sigma_{0}\right)$. If the experimental distribution is in agreement with a Weibull distribution, a straight line can be produced through the simple graphical representation of the data from regression analysis. The slope $m$ physically represents the Weibull modulus.

Good structural materials should have a high Weibull modulus, which means high repeatability of the strength values and high reliability of the material properties. The narrow distribution of defect size and the high flaw tolerance in the materials are means of improving the Weibull modulus. Without additional information the Weibull distribution in Eq. (2) is difficult to use because it contains many unknown variables. During 
the calculation of experimental data, the $\sigma$ values (tensile strength or elongation) are arranged in order of increasing value as follows:

$$
\sigma_{1} \leq \sigma_{2} \leq \sigma_{3} \cdots \leq \sigma_{f} \cdots \leq \sigma_{\mathrm{n}}
$$

A probability of failure is assigned to each $\sigma$ such that:

$$
P_{1} \leq P_{2} \leq P_{3} \cdots \leq P_{f} \cdots \leq P_{n}
$$

where $0 \leq P_{j} \leq 1$. Because the sample tested is considered representative of a large population, the true value of $P_{f}$ for each $\sigma_{f}$ is not known and has to be estimated. There are a number of statistical criteria that can be used to estimate the probability of failure $P_{f}$ [16], in which the most common approach is the median rank method, alternatively referred to as the Bernard method [17], which calculates the failure probability $P_{f}$ as

$$
P_{f}=(i-0.3) /(n+0.4)
$$

where $i$ is the ranked position of the specimen strength (or strain) in that set of castings and $n$ is the total number of specimens.

The scaling parameter $\sigma_{0}$ is determined by the $y$-intercept at $P_{f}=0.632$. The threshold parameter $\sigma_{u}$ is determined by calculation, during which a $\sigma_{u}$ is initially assumed and assigned in Eq. (2) to obtain the corresponding $\sigma$. The regression of the calculated $\sigma$ creates a linear equation and its coefficient of determination $\left(R^{2}\right)$. Therefore, by assuming a series of $\sigma_{u}$ at a value less than the minimum data of measurement, a number of $R^{2}$ can be obtained. Then the final threshold parameter $\sigma_{u}$ can be found from the corresponding equation that has the maximum $R^{2}$.

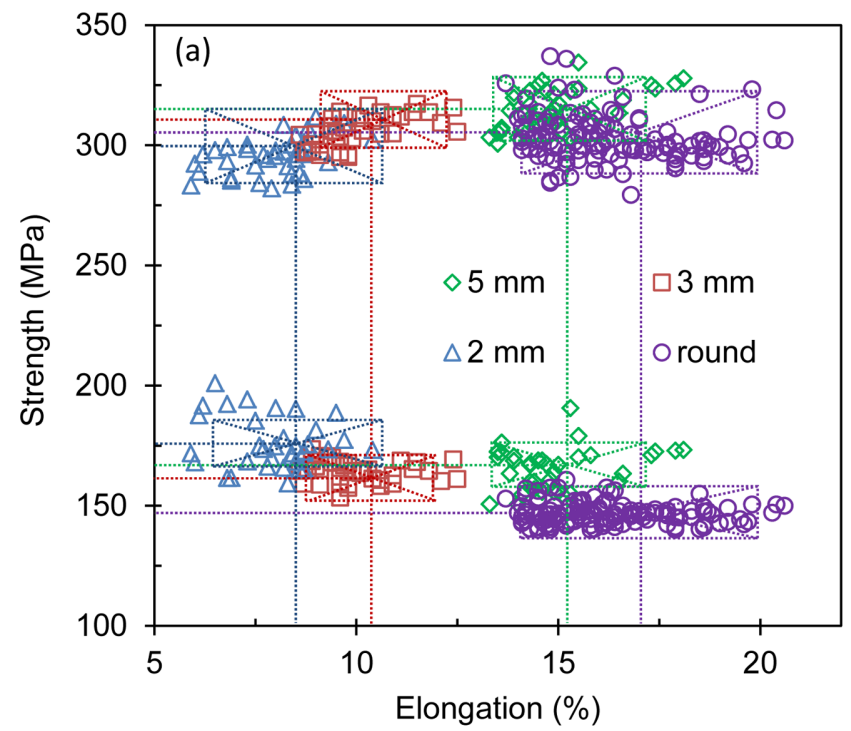

\section{RESULTS}

\subsection{Mechanical properties}

The measured tensile properties of the Al-Mg-Si-Mn alloy are shown in Fig. 2 for $99 \phi 6.35 \mathrm{~mm}$ round samples, 40 square samples for each thickness and 100 machined samples from 20 pieces of trial castings with two standard deviations (also termed as two-sigma). The average of the round samples was 146.6 MPa for yield strength, 302.7 MPa for UTS and $16.5 \%$ for elongation. The majority of the measured data were within the square defined by the two-sigma. This confirms the good consistence of the tensile properties. Meanwhile, the $2 \mathrm{~mm}$ square samples provided the $7.9 \%$ of elongation, 174.8 MPa of yield strength and 295.6 MPa of UTS. the $3 \mathrm{~mm}$ square samples provided the $10.2 \%$ of elongation, 164.2 MPa of yield strength and 306.0MPa of UTS. The $5 \mathrm{~mm}$ thick square samples had the $14.9 \%$ of elongation, $165.7 \mathrm{MPa}$ of yield strength and $314.9 \mathrm{MPa}$ of UTS. Furthermore, the machined samples were in square shape with two as-cast surfaces and two machined surfaces. The results in Fig. $2 b$ showed that the measured data were almost overlapping for the different locations, although slight differences could be observed. The total average was $9.44 \%$ of elongation, $151.3 \mathrm{MPa}$ of yield strength and 271.4 MPa of UTS. The averages of the measured data at each location were quite close to the total average because of the small standard deviations. However, the elongation and UTS at location 4 were lower than that at other locations, although the yield strength was still at a similar level. This means that location 4 was the weak area in the castings. Meanwhile, the tensile properties at location 1 showed a widest spread, and the tensile properties at locations 2 and

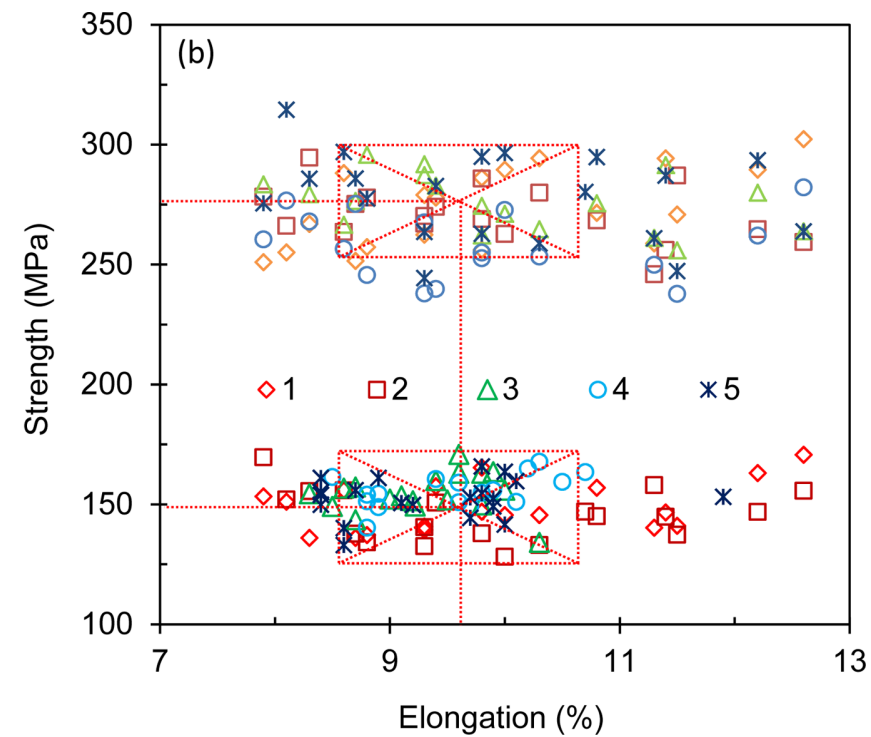

Fig. 2. The yield strength and the ultimate tensile strength (UTS) as a function of the elongation of (a) the as-cast standard $\phi 6.35$ mm round samples and the square samples with cross sections of $6.35 \times 2 \mathrm{~mm}, 6.35 \times 3 \mathrm{~mm}$ and $6.35 \times 5 \mathrm{~mm}$, (b) the machined samples with a cross section of $6.35 \times 2.8 \mathrm{~mm}$ from the trial castings at different locations. The squares represent the value of two times standard deviation of the tested samples and the centre of squares is the average value of tested data. 
Table 1. The average values and standard deviations of the measured yield strength, ultimate tensile strength and elongation of the tensile samples with as-cast surface or with machined surface

\begin{tabular}{|c|c|c|c|c|c|c|c|c|}
\hline \multirow[b]{2}{*}{ Sample type } & \multirow{2}{*}{\multicolumn{2}{|c|}{$\begin{array}{l}\text { Sample label and } \\
\text { dimension }\end{array}$}} & \multicolumn{2}{|c|}{ Elongation (\%) } & \multicolumn{2}{|c|}{ Yield strength (MPa) } & \multicolumn{2}{|c|}{ Ultimate tensile strength $(\mathrm{MPa})$} \\
\hline & & & Average & $\begin{array}{c}2 \text { (standard } \\
\text { deviation) }\end{array}$ & Average & $\begin{array}{l}2 \text { (standard } \\
\text { deviation) }\end{array}$ & Average & $\begin{array}{l}\text { 2(standard } \\
\text { deviation) }\end{array}$ \\
\hline \multirow[t]{2}{*}{ Round sample } & & $\phi 6.35 \mathrm{~mm}$ & 16.47 & 3.24 & 146.63 & 8.64 & 302.70 & 19.11 \\
\hline & & $2 \times 6.35 \mathrm{~mm}$ & 7.98 & 2.11 & 174.79 & 20.90 & 295.61 & 15.36 \\
\hline \multirow[t]{4}{*}{ Square sample } & & $3 \times 6.35 \mathrm{~mm}$ & 10.16 & 2.31 & 164.23 & 9.06 & 305.99 & 13.76 \\
\hline & & $5 \times 6.35 \mathrm{~mm}$ & 14.91 & 2.52 & 165.75 & 17.25 & 314.93 & 17.91 \\
\hline & 1 & $2.8 \times 6.35 \mathrm{~mm}$ & 9.90 & 1.40 & 148.87 & 20.81 & 273.78 & 33.05 \\
\hline & 2 & $2.8 \times 6.35 \mathrm{~mm}$ & 9.91 & 1.12 & 145.36 & 21.54 & 270.82 & 23.30 \\
\hline \multirow{4}{*}{$\begin{array}{l}\text { Machined square } \\
\text { sample* }\end{array}$} & 3 & $2.8 \times 6.35 \mathrm{~mm}$ & 9.29 & 0.57 & 154.39 & 16.60 & 275.73 & 23.45 \\
\hline & 4 & $2.8 \times 6.35 \mathrm{~mm}$ & 8.74 & 1.08 & 155.66 & 13.89 & 258.38 & 27.74 \\
\hline & 5 & $2.8 \times 6.35 \mathrm{~mm}$ & 9.36 & 0.90 & 152.35 & 16.35 & 278.34 & 36.88 \\
\hline & & Total average & 9.44 & 1.01 & 151.32 & 17.84 & 271.41 & 28.88 \\
\hline
\end{tabular}

Note: *the digital 1, 2, 3, 4, and 5 represents the location of samples from the trial casting shown in Figure 1.

3 showed a very similar distribution in comparison with the data among the 5 different locations defined in Fig. 1.

The results in Fig. 2 and Table 1 show that the thinner samples exhibited lower elongation and lower UTS, but higher yield strength for square samples. In comparison of the tensile properties obtained by the round and the square tensile samples, the yield strength, UTS and elongation were all higher for the round samples. In particular, the average elongation of the round samples was doubled over that of the $2 \mathrm{~mm}$ thick square samples, although the yield strength was higher and the UTS was lower for the $2 \mathrm{~mm}$ thick square samples. On the other hand, it is also seen that an overlapping among the measured data for the different types of samples. The overlapping had different levels, but over 35\% of the measured strength was seen at similar levels, which indicates that the overlapping of the data is significant. Overall, it is seen that the application of average value with standard deviations is capable of assessing the tensile properties, but the overlapping is significant. It is thus very rough to differentiate the data scatter and error distribution in the trial castings.

\subsection{Assessing the repeatability via Weibull analysis}

In order to assess the repeatability using Weibull analysis, the data in Fig. 2 was reorganised in ascending order for the calculated $P_{f}$ value according to Eq. (5). Figure 3 shows the representative Weibull plots of the UTS obtained from the as-cast round samples. The solid lines were the corresponding linear fit with Eq. (2) at different levels of $\sigma_{u}$. Then the best-fit line was obtained by the maximum Rsquare value. After finding the maximum R-square value, it was immediately used to evaluate the applicability of the Weibull distribution for the measured results by utilising a goodness-of-fit. For assessing the goodness-of-fit, the critical values of $\mathrm{R}^{2}$ with $\alpha=0.05\left(R_{0.05}^{2}\right)$ was calculated according to the formula [18].

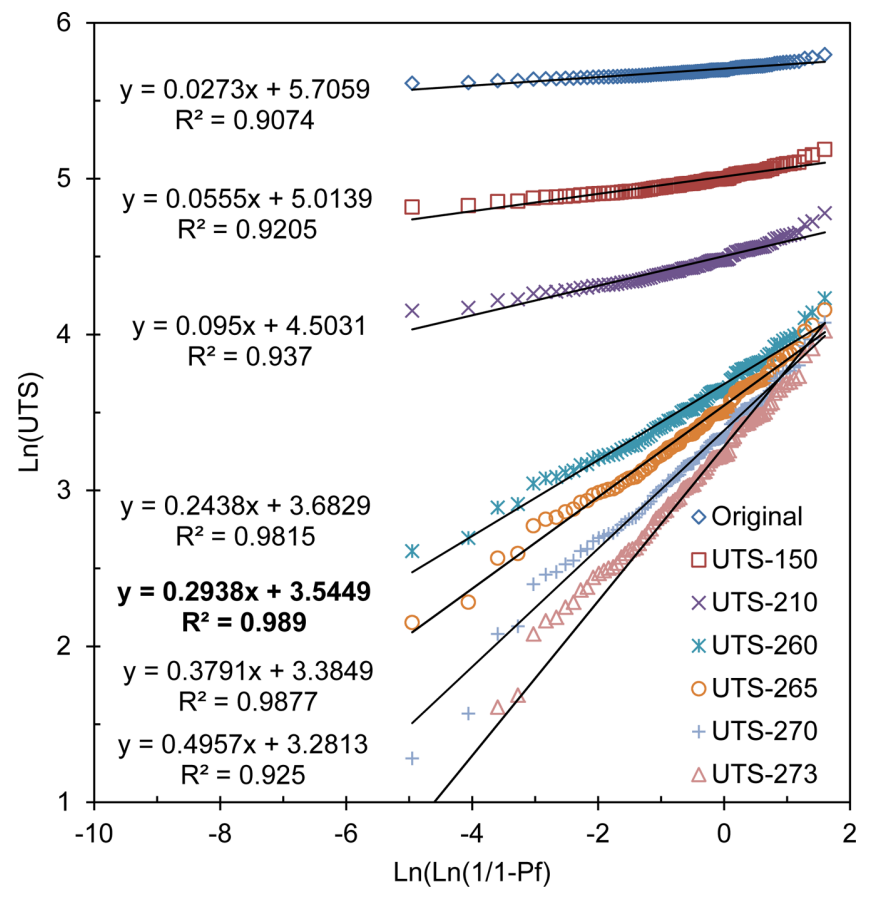

Fig. 3. Weibull plots for the UTS of Al-Mg-Si-Mn alloy obtained from the round standard tensile test bars that were directly cast by HPDC process.

$$
R_{0.05}^{2}=1.0637-\frac{0.4174}{n^{0.3}}
$$

For the as-cast round samples, the sample number was 99 , the calculated $R_{0.05}^{2}$ was 0.9585 . The principle of assessing the measured data is that the Weibull distribution is not applicable if the $R^{2}$ of the linear regression from the Weibull probability plot is less than the value of $\mathrm{R}^{2}$ with $\alpha=0.05$. This means that the $R^{2}$ from the regression equation needs to be larger than the $R_{0.05}^{2}$ in order to satisfy the Weibull distribution. By comparing the $\mathrm{R}^{2}=0.9585$ from the Eq. (6), the $\mathrm{R}^{2}$ value was 0.9759 for the best-fit line in Fig. 5 for the as-cast 

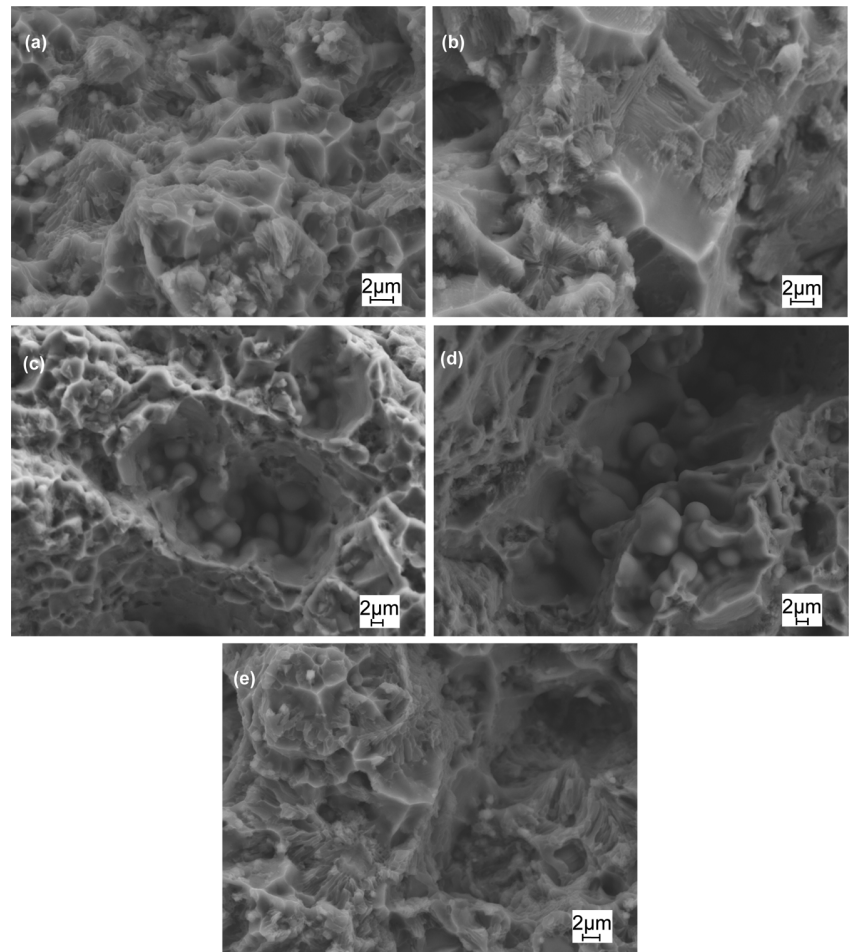

Fig. 4. Typical detailed fractographs on a cross section of die-cast tensile samples with a cross section of (a) $\phi 6.35 \mathrm{~mm}$, (b) $5 \times 6.35 \mathrm{~mm}$, (c) $3 \times 6.35 \mathrm{~mm},(\mathrm{~d}) 2 \times 6.35 \mathrm{~mm}$, and (e) $2.8 \times 6.35 \mathrm{~mm}$ with machined surface.

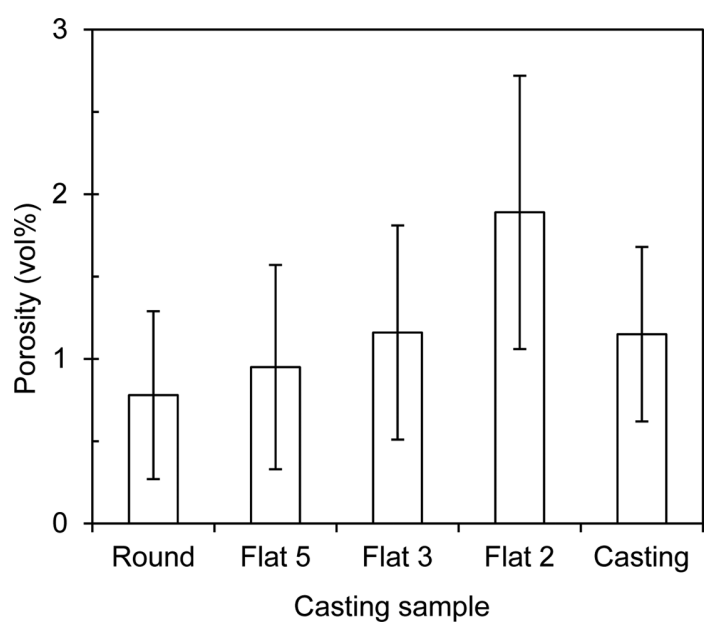

Fig. 5. The porosity levels of the tensile samples obtained from the different shapes and surface conditions. 'Round' represents the $\phi 6.35 \mathrm{~mm}$ sample; 'Flat 5' represents the $5 \times 6.35 \mathrm{~mm}$ sample; 'Flat 3 ' represents the $3 \times 6.35 \mathrm{~mm}$ sample; 'Flat 2 ' represents the $2 \times 6.35 \mathrm{~mm}$ sample; 'Casting' represents the $2.8 \times 6.35 \mathrm{~mm}$ sample machined from the trial castings.

round samples. The higher $\mathrm{R}^{2}$ value in Fig. 5 means that the measured data can be well described by Weibull distribution. By using the same methodology, the statistic results were obtained for different parameters with different types of samples. Table 2 lists the characteristic parameters in Weibull distribution of the yield strength, UTS and elongation of the tensile samples with as-cast surface and with machined surface.

The R-square data in Table 2 confirmed that the tensile test data can be adequately modelled by three-parameter Weibull statistical analysis. For the yield strength, the as-cast round samples had a maximum Weibull modulus, which indicates that the as-cast round samples exhibited a best reliability, repeatability and reproducibility. Meanwhile, the machined samples exhibited the second best of Weibull modulus, which means that the machined samples have better repeatability than the as-cast square samples. Among those square samples the $2 \mathrm{~mm}$ thick samples had the lowest and the $5 \mathrm{~mm}$ thick samples had the highest Weibull modulus. This indicates that the repeatability was worsened for the castings with thinner wall thickness. The square samples showed a lower value of Weibull modulus than the machined samples and the as-cast round samples. On the other hand, as described above, the parameters $\sigma_{0}$ and $\sigma_{u}$ are preferred to be higher in the castings because no sample is expected to fail below $\sigma_{u}$ and the probability of failure is $63.2 \%$ at $\sigma_{0}$. However, it was not observed the highest $\sigma_{u}$ for the yield strength, UTS in the as-cast round samples and only the $\sigma_{u}$ for elongation is the highest value. On the other hand, although slight inconsistent in the parameters for elongation, the as-cast samples provided the higher $\sigma_{u}$. This means the samples with as-cast surface provided better strength than the machined samples. When reviewing the data of $\sigma_{0}$, the results showed that the as-cast round samples had the highest value and the machined samples had the second best results. This is consistent with the data of Weibull modulus $(m)$. Overall, comparing the as-cast round samples and the as-cast square samples, the as-cast round samples showed good repeatability and reliability. It was expected that the machined samples would show worse ductility than the as-cast samples because of the removal of casting surface. However, good performance as described by the Weibull parameters was shown through the different types of samples. The repeatability and reliability of the machined samples was reasonably good, although the strength under which the samples were not failed was slightly lower than the directly cast samples. It is important to note that the values in the Weibull parameters for the as-cast square samples, in particular the $3 \mathrm{~mm}$ thick square samples were relatively close to those obtained from the machined samples.

\subsection{Fractography and microstructure}

The fractographic observations were carried out on the fractured samples, which had the characteristic parameters close to $\sigma_{0}$. The fractographic micrographs of the as-cast and machined samples are shown in Fig. 4. On the fractured surfaces, it was always seen a layer with smooth fracture on the casting surface and a coarse fracture area in the central 
Table 2. Calculated parameters in Weibull statistics analysis of the yield strength, ultimate tensile strength and elongation of the tensile samples with as-cast surface and with machined surface

\begin{tabular}{|c|c|c|c|c|c|}
\hline Property & Sample & $m$ & $\sigma_{\mathrm{u}}$ & $\sigma_{0}$ & $\mathrm{R}^{2}$ \\
\hline \multirow{5}{*}{ Yield strength } & $\phi 6.35 \mathrm{~mm}$, as-cast surface & 4.43 & 131 & 26.78 & 0.9899 \\
\hline & $5 \times 6.35 \mathrm{~mm}$, as-cast surface & 2.54 & 145 & 23.36 & 0.9612 \\
\hline & $3 \times 6.35 \mathrm{~mm}$, as-cast surface & 2.78 & 145 & 18.67 & 0.9747 \\
\hline & $2 \times 6.35 \mathrm{~mm}$, as-cast surface & 1.65 & 158 & 14.82 & 0.9755 \\
\hline & $2.8 \times 6.35 \mathrm{~mm}$, machined surface & 3.92 & 117 & 37.71 & 0.9885 \\
\hline \multirow{5}{*}{$\begin{array}{l}\text { Ultimate tensile } \\
\text { strength (UTS) }\end{array}$} & $\phi 6.35 \mathrm{~mm}$, as-cast surface & 4.17 & 260 & 43.82 & 0.9759 \\
\hline & $5 \times 6.35 \mathrm{~mm}$, as-cast surface & 2.81 & 297 & 19.17 & 0.9728 \\
\hline & $3 \times 6.35 \mathrm{~mm}$, as-cast surface & 2.71 & 293 & 17.67 & 0.9425 \\
\hline & $2 \times 6.35 \mathrm{~mm}$, as-cast surface & 2.11 & 279 & 14.86 & 0.9787 \\
\hline & $2.8 \times 6.35 \mathrm{~mm}$, machined surface & 3.34 & 223 & 54.26 & 0.9924 \\
\hline \multirow{5}{*}{ Elongation } & $\phi 6.35 \mathrm{~mm}$, as-cast surface & 4.81 & 13.2 & 11.36 & 0.9913 \\
\hline & $5 \times 6.35 \mathrm{~mm}$, as-cast surface & 2.40 & 4.5 & 3.88 & 0.9837 \\
\hline & $3 \times 6.35 \mathrm{~mm}$, as-cast surface & 1.89 & 8.5 & 3.84 & 0.9904 \\
\hline & $2 \times 6.35 \mathrm{~mm}$, as-cast surface & 1.32 & 3.7 & 2.68 & 0.9671 \\
\hline & $2.8 \times 6.35 \mathrm{~mm}$, machined surface & 3.50 & 7.4 & 5.48 & 0.9814 \\
\hline
\end{tabular}

area of the samples. Multiple failure sources were observed on the fracture surfaces of each type of the samples; hence the normal failure mechanism was plausibly caused by internal defects in the corresponding casting. Porosities were also observed on the fracture surfaces, which were particularly severe in the square samples with $2 \mathrm{~mm}$ and 3 $\mathrm{mm}$ thickness. The porosities were seldom observed in the as-cast round samples, but frequently seen in the $2 \mathrm{~mm}$ square samples.

Furthermore, the porosity levels were quantitatively measured using optical microscope on the as-polished metallographic surfaces of the different type samples, which were also selected from the castings made under the same batch as the fractured samples. The results are shown in Fig. 5. The average porosity levels were from $0.8 \mathrm{vol} \%$ to $1.9 \mathrm{vol} \%$. The as-cast round samples had the least amount of porosities and the as-cast $2 \mathrm{~mm}$ thick square samples had the highest amount of porosities. The porosity levels in the trial castings were similar with that in the $3 \mathrm{~mm}$ thick square samples; both of them were higher than that in the as-cast round samples. The results of porosity levels are consistent with the parameters obtained from Weibull analysis, in which the samples with less porosity provided the increased Weibull modulus, threshold parameter and scaling parameter. Therefore, the improvement of repeatability, the increase of the failed strength and the failure probability of $63.2 \%$ were achieved.

Generally, microstructure plays a key role in determining the materials tensile properties. Therefore, the as-cast microstructures were examined for the different types of samples. The similar results were observed in different casting samples. Figure 6 shows the microstructure on a cross section of the die-cast tensile samples. As seen, the microstructure showed an apparent skin layer with less primary $\alpha$-Al phase. The
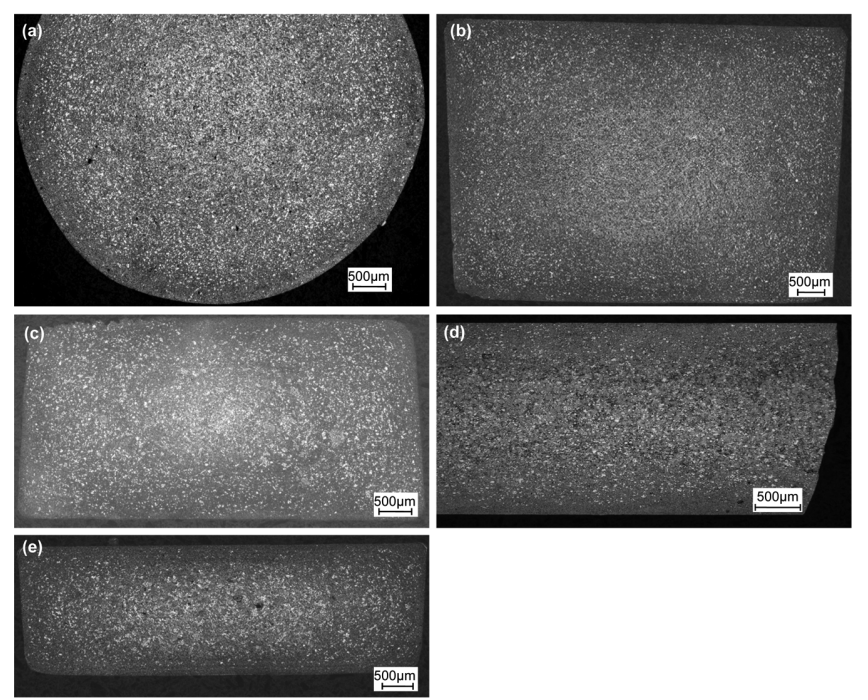

Fig. 6. Optical micrographs showing the microstructure of the die-cast tensile samples on a cross section of (a) $\phi 6.35 \mathrm{~mm}$, (b) $5 \times 6.35 \mathrm{~mm}$, (c) $3 \times 6.35 \mathrm{~mm}$, (d) $2.8 \times 6.35 \mathrm{~mm}$ with machined surface, and (d) $2 \times 6.35 \mathrm{~mm}$.
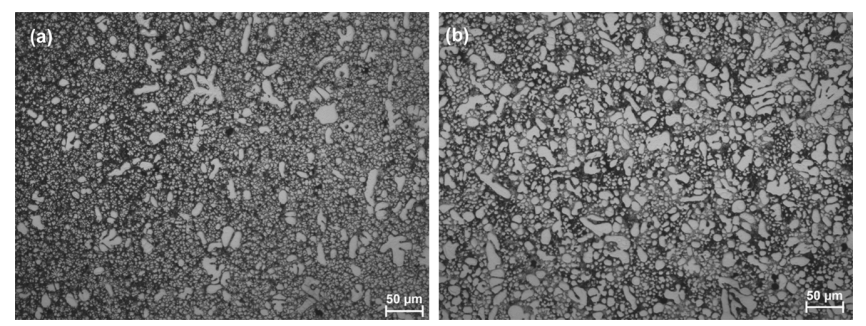

Fig. 7. Optical micrographs showing the representative microstructure of the die-cast tensile samples made directly from HPDC process, (a) near the sample surface and (b) near the sample centre.

thick samples exhibited severe segregations. However, the detail microstructures were very similar in the skin region 
and the central region of different samples. Figure 7 shows the representative microstructure in the skin region and the central region of castings. The mixture of coarse and fine primary $\alpha$-Al grains was observed, although the centre had coarser primary $\alpha-\mathrm{Al}$ grains and slightly increased defect levels. From these results, the microstructural uniformity and defect levels are the fundamentals to result in the difference in the tensile properties and in the Weibull parameters obtained in the Weibull statistical analysis.

\section{DISCUSSION}

The experimental results showed that the levels of porosity and the uniformity of microstructure are responsible for the variation of both the tensile properties and the Weibull parameters of high pressure die-cast $\mathrm{Al}-\mathrm{Mg}$-Si-Mn alloy samples. Therefore, understanding the correlations between the observed microstructure, the tensile properties and the Weibull parameters is important to find out the repeatability and reliability of the castings.

The non-uniform microstructure in die-cast aluminium alloys is formed in the unique solidification process in HPDC process. This has been reported in our previous publications [19,20]. A uniform microstructure can provide better distribution of solute elements in the primary $\alpha$-Al phase and the distribution of eutectic $\mathrm{Al}-\mathrm{Mg}_{2} \mathrm{Si}$ phase. The sizes of the primary $\alpha$-Al phase and the eutectic Al- $\mathrm{Mg}_{2} \mathrm{Si}$ phase have no apparent difference from the skin region to the central region. This results in a much less accumulation of the local stress, and even uniform distribution of stress concentration under loading. Therefore, the capability to bear the maximum stress level can be increased and the difference from one to another casting is reduced, which means that the repeatability of casting production is improved. However, in the complicated casting structure and the individually different gating system, the turbulence flow is difficult to be avoided during casting process. Therefore, the uniform microstructure is difficult to be obtained in high pressure die castings. Therefore, the improvement of property repeatability may be more significant through minimising the defects level in the castings.

The improvement of tensile properties from the reduction of defects levels can alter the parameters in the Weibull statistical distribution. This is because the porosity is randomly distributed in the castings. The increased porosity can increase the possibility of fracture under stress and increase the uncertainty of breakage under the maximum stress, thus increase in the scatter of the measured data, which is characterised by the smaller Weibull modulus (Table 2). Consequently, the repeatability becomes worse. Therefore, the reduction of internal defects in die-castings is an effective approach to increase the tensile properties and obtain better repeatability and reliability in application.

\section{CONCLUSIONS}

(1) The repeatability and reliability of castings made by die-cast Al-Mg-Si-Mn alloy can be modelled by three-parameter Weibull analysis because of the high $\mathrm{R}$-square value in the linear fitting of experimental data.

(2) The round samples had the maximum Weibull modulus for the modelled yield strength, thus showed the best repeatability. The machined samples exhibited the second best of Weibull modulus, which indicates that the repeatability of machined samples is better than the square samples. Among the square samples, the $2 \mathrm{~mm}$ thick samples had the lowest and the $5 \mathrm{~mm}$ thick samples had the highest Weibull modulus, indicating that the repeatability was worsened for the castings with thinner wall thickness.

(3) The microstructural uniformity and porosity levels play critical roles in determining the repeatability of high pressure die-castings. A less segregation in the microstructure can uniform the stress distribution and a less porosity in the casting can reduce the sources for brittle fracture. These can improve the repeatability in casting production.

\section{ACKNOWLEDGEMENT}

The authors acknowledge the Engineering and Physical Sciences Research Council (EPSRC), Technology Strategy Board (TSB) and Jaguar Land Rover (JLR) in United Kingdom for financial support.

\section{REFERENCES}

1. European Aluminium Association, Aluminium in Cars, http://www.alueurope.eu/pdf/Aluminium_in_cars_Sept2008.pdf (Accessed April 10, 2015).

2. Jaguar Land Rover Sustainability Report 2012/13, http:// www.jaguarlandrover.com/media/ 22638/Sustainability-Report1213-Interactive-080114.pdf (Accessed April 10, 2015).

3. D. Carle and G. Blount, Mater. Design 20, 267 (1999).

4. A. Jambor and M. Beyer, Mater. Design 18, 203 (1997).

5. S. Ji, D. Watson, and Z. Fan, Mat. Sci. Eng. A 556, 824 (2012).

6. S. Ji, D. Watson, Y. Wang, M. White, and Z. Fan, Mater. Sci. Forum 765, 23 (2013).

7. M. R. Barone, Int. J. Eng. Sci. 38, 1279 (2000).

8. F. Bonollo, N. Gramegna, and G. Timelli, JOM67, 901 (2015).

9. G. Timelli and F. Bonollo, Metallurgical Science and Technology, 26-1, 2 (2008).

10. G. Timelli and F. Bonollo, Mater. Sci. Eng. A 528, 273 (2010).

11. J. Campbell, Castings, 2nd Ed., pp.273-283, ButterworthHeinemann, Oxford (2003).

12. M. Elgueta, G. Díaz, S. Zamorano, and P. Kittl, Mater. Design 28, 2496 (2007). 
13. N. R. Green and J. Campbell, Mater. Sci. Eng. A 173, 261 (1993).

14. S. Ji, W. Yang, F. Gao, D. Watson, and Z. Fan, Mater. Sci. Eng. A 564, 130 (2013).

15. V. Fuis and T. Navrat, An International Journal of Science, Engineering and Technology, World Academy of Science, Engineering and Technology 58, 642 (2011).

16. S. Kirtay and D. Dispinar, Effect of Ranking Selection on the Weibull Modulus Estimation, Gazi University Journal of Science 25, 175 (2012).
17. A. R. Rao and K. H. Hamed, Frequency Analysis, pp.350364, CRC Press, Florida (2000).

18. M. Tiryakioglu, D. Hudak, and G. Okten, Mater. Sci. Eng. A. 527, 397 (2009).

19. S. Ji, Y. Wang, D. Watson, and Z. Fan, Metall. Mater. Trans. A 44, 3185 (2013).

20. S. Ji, Y. Wang, D. Watson, and Z. Fan, Mater. Sci. Forum 783, 234 (2014). 